\title{
Effect of Nonspecific Chronic Low Back Pain on Walking Economy: An Observational Study
}

Alberito Rodrigo Carvalho, Welds Rodrigo Ribeiro Bertor, Ronaldo Valdir Briani, Gabriela Matté Zanini, Lígia Inez Silva, Alexandro Andrade \& Leonardo Alexandre Peyré-Tartaruga

To cite this article: Alberito Rodrigo Carvalho, Welds Rodrigo Ribeiro Bertor, Ronaldo Valdir Briani, Gabriela Matté Zanini, Lígia Inez Silva, Alexandro Andrade \& Leonardo Alexandre Peyré-Tartaruga (2016) Effect of Nonspecific Chronic Low Back Pain on Walking Economy: An Observational Study, Journal of Motor Behavior, 48:3, 218-226, DOI: 10.1080/00222895.2015.1079162

To link to this article: https://doi.org/10.1080/00222895.2015.1079162

曲 Published online: 24 Sep 2015.

Submit your article to this journal

Џ Article views: 132

View Crossmark data ¿

Citing articles: 2 View citing articles $\longleftarrow$ 
RESEARCH ARTICLE

\title{
Effect of Nonspecific Chronic Low Back Pain on Walking Economy: An Observational Study
}

\author{
Alberito Rodrigo Carvalho ${ }^{1,4}$, Welds Rodrigo Ribeiro Bertor ${ }^{1}$, Ronaldo Valdir Briani ${ }^{2}$, \\ Gabriela Matté Zanini ${ }^{1}$, Lígia Inez Silva ${ }^{1}$, Alexandro Andrade ${ }^{3}$, Leonardo Alexandre Peyré-Tartaruga ${ }^{4}$ \\ ${ }^{1}$ Fisioterapia, Clínica de Fisioterapia (Unioeste), Universidade Estadual do Oeste do Paraná, Cascavel, Brazil. ${ }^{2}$ Fisioterapia, \\ Universidade Estadual Paulista, Presidente Prudente, Brazil. ${ }^{3}$ Educação Física, Universidade Estadual de Santa Catarina, \\ Florianópolis, Brazil. ${ }^{4}$ Educação Física, Universidade Federal do Rio Grande do Sul, Porto Alegre, Brazil.
}

\begin{abstract}
The authors investigated the effects of chronic low back pain (LBP) and walking speed (WS) on metabolic power and cost of transport (CT). Subjects with chronic nonspecific LBP (LBP group [LG]; $n=9$ ) and healthy (control group [CG]; $n=9$ ) were included. The test battery was divided into 3 blocks according to WS as follows: preferred self-selected speed (PS), and lower and higher than the PS. In each block, the volunteers walked 5 min, during which oxygen consumption was measured. Although without differences between groups, the LG had CT lower in slower speeds than in faster speeds. Walking speed affected CT only in the LG, which the group had the greatest walking economy at slower speeds.

Keywords: low back pain, human locomotion, walking
\end{abstract}

A $\mathrm{n}$ important marker of human evolution is the adoption of locomotion on two legs as an exclusive form of gait, as energy saving is one of the major reasons for the establishment of this type of locomotion (Pontzer, Raichlen, \& Sockol, 2009; Skoyles, 2006).

Humans tend to walk in gait patterns such as horizontal velocity and stride frequency and length, which are freely chosen according to the preferred form of locomotion. Such choices affect gait economy because it minimizes the metabolic cost and, therefore, leads to an optimal walking speed (Donelan, Kram, \& Kuo, 2001). Optimal walking speed has been defined as the walking speed at which mechanical parameters, gait characteristics, and lower metabolic cost are simultaneously optimized (Leurs et al., 2011). Deviation from these preferred patterns increases the energy cost of locomotion.

Cost of transport (CT) is a measure of locomotion economy and represents the amount of metabolic energy consumed to move $1 \mathrm{~kg}$ of body mass per distance unit, expressed as $\mathrm{J} \cdot \mathrm{kg}^{-1} \cdot \mathrm{m}^{-1}$ (Cunningham, Schilling, Anders, \& Carrier, 2010; Saibene \& Minetti, 2003), and provides metabolic information on gait quality. As the integrity of the walk characteristics contribute to its economy and may be deteriorated by pathological conditions (Christiansen, Schenkman, McFann, Wolfe, \& Kohrt, 2009; Mahaudens, Detrembleur, Mousny, \& Banse, 2009; Waters \& Mulroy, 1999; Wert, Brach, Perera, \& van Swearingen, 2010), determining the extent of the impact of certain diseases on gait economy has become important, especially for rehabilitation professionals. Although the prevalence of low back pain is high (Ehrlich, 2003; Welch, 2012), the walking economy in people with low back pain has received poor attention.
According to some biomechanics studies, an impairment in the quality of metabolic walk is likely in patients with chronic low back pain as a result of impairment in gait pattern (Brumagne, Janssens, Janssens, \& Goddyn, 2008; Brumagne, Janssens, Knapen, Claeys, \& Suuden-Johanson, 2008; Lamoth, Daffertshofer, Meijer, \& Beek, 2006; Lamoth et al., 2002). Meanwhile, reports on the correlation between energy production capacity and various factors that dominate the biopsychosocial mechanisms underlying the etiology of low back pain are often contradictory. Doubts still remain whether chronic lumbar pain status causes fitness loss and impairs performance in functional activities, which might lead to altered optimal walking speed and, therefore, high energy cost of walking (AlObaidi, Al-Zoabi, Al-Shuwaie, Al-Zaabie, \& Nelson, 2003; Heneweer, Staes, Aufdemkampe, Van Rijn, \& Vanhees, 2011; Huijnen et al., 2010; Smeets et al., 2006; Smeets, van Geel, \& Verbunt, 2009; Wittink, Hoskins Michel, Wagner, Sukiennik, \& Rogers, 2000).

According to a review, patients with low back pain have modified walking patterns because the pain alters mechanical, physiological, and psychological parameters during walking. The authors suggest that these alterations can possibly impair the energy-minimizing mechanisms. The most acceptable model of energy minimization is the inverted pendulum, which represents exchanges between potential and kinetic energies linked to the center of mass, which in turn saves metabolic energy, producing the most economical walk. Thus, the changes in walking patterns described in low back pain can make the exchange between the mechanical energies of the center of mass least effective, damaging the energy-minimizing mechanism and making walking most expensive metabolically (Carvalho, Andrade, \& Peyré-Tartaruga, 2015). To the best of our knowledge, this is the first study to specifically evaluate the CT in chronic low back pain and if the biomechanics adjustments caused by the walking speed in patients with low back pain can change it. This knowledge can contribute for rehabilitation guidelines when walking is considered as an intervention.

Correspondence address: Alberito Rodrigo Carvalho, Universidade Estadual do Oeste do Paraná, Fisioterapia, Clínica de Fisioterapia (Unioeste), Rua Universitária, 2069, Jd Univeritário, Cascavel, 85819-110 Brazil.e-mail: alberitorodrigo@gmail.com 
The aims of this study were to verify (a) the effect of chronic low back pain (group effect) on metabolic power and CT and (b) the effect of walking speed (WS) on these variables. Consequently, considering the fact that low back pain sufferers tend to walk slower than subjects without low back pain and, maybe, that if they walk faster they can become more economical, we tested the following hypotheses: (a) walking economy is reduced in patients with chronic low back pain of nonspecific etiology and (b) the CT decreases as the speed increases in patients with low back pain indicating improvement in walking economy, with the CT lower in these subjects at highest velocities because, at this velocities, they could be near the optimal walking speed.

\section{Methods}

\section{Participants}

This study was approved by the Ethics Committee on Human Research of the State University of West of Paraná (UNIOESTE) under protocol 1433/2011 and classified as an observational, ex post facto, exploratory-descriptive, transversal study. All of the volunteers in this study signed a free informed consent form prior to participation.

Prior to the recruitment of volunteers, the sample calculation was performed. To determine the standard deviations of CT in patients with low back pain, a sample calculation was performed by using estimated data from another pathological gait study (Waters \& Mulroy, 1999). The sample calculation was performed using software WinPepi 11:18 (PEPI for Windows). The input data for the calculation were: statistical power, $80 \%$; 5\% significance level; standard deviations: control group [CG], 0.4; low back pain group [LG], 0.6; difference to be detected, 0.8; one-tailed $t$ test. There was a need for a minimum of 16 volunteers in total (eight for each group). Considering possible losses, 18 volunteers were recruited.

Volunteers with chronic nonspecific low back pain, of both sexes, between 25 and 59 years old, from the UNIOESTE Physical Rehabilitation Center were recruited intentionally, not probabilistically, to compose the LG. The CG consisted of subjects without systemic or musculoskeletal disorders, either chronic or acute, in the lower limbs or spine, and were matched according to age, weight, and height in relation to the LG.

Volunteers, from both groups, were not included if they were smokers or ex-smokers for a period of at least five years; systematically and routinely engaged in physical exercise two or more times per week for at least $30 \mathrm{~min}$; and showed obvious differences in length of the lower limbs, postural misalignments, and body mass indexes greater than $30.0 \mathrm{~kg} \cdot \mathrm{m}^{-2}$.

Because of the known difficulty in identifying the primary cause of low back pain, the inclusion criteria for the LG followed the recommendations of original or review articles that focused on the diagnosis and treatment of low back pain, according to the signs and symptoms indicated in the anamnesis and physical examination (Chou et al., 2007; Koes et al., 2010; Krismer \& van Tulder, 2007; Lamoth, Beek, \& Meijer, 2002; Negrini, Fusco, Atanasio, Romano, \& Zaina, 2008). Thus, volunteers should report low back pain persisting for more than three months, without radiation to the lower limbs but with physical and clinical characteristics compatible with category 1 pain (nonspecific low back pain) according to the guidelines for evaluation and treatment that are proposed by the American College of Physicians and the American Pain Society (Chou et al., 2007).

The exclusion criteria for the LG were as follows: patients with low back pain whose clinical history suggests a specific etiology; identification of red flags suggesting need for medical referral; patients with osteomuscular injuries in other joints and neurological diseases; patients with histories of spinal surgery, pregnancy, cardiovascular, or lung diseases, or limitation of walking ability in relation to the preferred self-selected speed (PS); and significant increase in pain during the tests, to the point that walking activity becomes intolerable according to the patient's perception (Chou et al., 2007; Leerar, Boissonnault, Domholdt, \& Roddey, 2007).

\section{Procedures}

After receiving explanations of the procedures and objectives of the research, the volunteers underwent clinical screening for the identification of possible exclusion factors and for collection of history and anthropometric data. Body mass indexes was calculated as the ratio between body mass $(\mathrm{kg})$ and height $\left(\mathrm{m}^{2}\right)$. The volunteers were categorized according body mass indexes $\left(\mathrm{kg} \cdot \mathrm{m}^{-2}\right)$ as follows: underweight $(<18.5)$, ideal weight $(18.5-24.9)$, overweight (25-29.9), obese class 1 (30-34.9), obese class 2 (35-39.9), and obese class 3 (>40; Hergenroeder, Wert, Hile, Studenski, \& Brach, 2011). The length of the lower limbs (m) was obtained by measuring the length from the greater trochanter to the ground through the lateral malleolus in the orthostatic position without shoes (Elbaz et al., 2009). On this occasion, the subject underwent a familiarization period, for $5 \mathrm{~min}$, on the treadmill (Embrex 563-R3, Brusque, Brazil). After familiarization, the PS was determined.

The PS was determined on the treadmill as follows: (a) the volunteer was asked to choose the most comfortable speed, similar to the one used daily, that could be maintained over a long path; (b) the treadmill speed was increased progressively up to a standard of $7 \mathrm{~km} \cdot \mathrm{hr}^{-1}$ (or until before the volunteer felt insecure walking) and then reduced in the same pattern so that the volunteer could choose the PS in each set; (c) the PS of each patient was determined by calculating the mean of the PSs from two sets of recording (Dingwell \& Marin, 2006).

The sampling took place in the Research Laboratory of Human Movement of UNIOESTE (Cascavel/PR - Brazil). To measure oxygen consumption $\left(\mathrm{VO}_{2}\right)$, the gas analyzer 
$\mathrm{VO}_{2000}$ model (Inbramed, St. Paul, MN) was attached to a computer connected to a medium-flux pneumotachograph device $\left(10-120 \mathrm{~L} \cdot \mathrm{min}^{-1}\right)$, duly calibrated at the beginning of each test by using a pump with oxygen, carbon dioxide, and microparticle sampling valve integrated to the external software Aerograph (Inbramed, St. Paul, MN). The sampling rate for the analysis of oxygen consumption was one point every $10 \mathrm{~s}$.

Initially, the subjects remained seated for $5 \mathrm{~min}$ to ensure that the hemodynamic parameters were in the resting levels. Parameters such as heart rate and blood pressure were measured only to ensure that the volunteers were medically fit to walk. Volunteers with resting blood pressure $\geq 150$ / $100 \mathrm{~mm} \mathrm{Hg}$ and/or heart rate $\geq 110$ beats/min were excluded from the data analysis. However, the volunteers were told that they should not be embarrassed to stop the test if they felt a significant increase in pain during the test.

After the tests, the volunteers were asked to remain in orthostatic position, as still as possible, for $6 \mathrm{~min}$ for the collection of $\mathrm{VO}_{2}\left(\mathrm{VO}_{2}\right.$ orthostatic $)$.

The test battery was divided into three blocks according to walking speed. Only three speeds were proposed to avoid overloading on the lumbar group. In the first block, the subjects walked at their previously determined PS. The order of the next two blocks was randomly selected so that in one case, the volunteers walked at a speed lower than that in the PS (LOW: $0.5 \mathrm{~km} \cdot \mathrm{hr}^{-1}$ slower than the PS) and in the other, the volunteers walked at a speed higher than that in the PS (UP: $0.5 \mathrm{~km} \cdot \mathrm{hr}^{-1}$ faster than the PS).

In each block, the subjects walked for 5 min to stabilize the balance between the consumption and utilization of oxygen. After completing each block, the volunteer remained seated for measurements of resting heart rate and blood pressure. The criterion for the new test block to be initiated was the return of oxygen consumption to resting levels.

The fluctuation curves of $\mathrm{VO}_{2}$ in the orthostatic position and in each of the three blocks of the test battery were smoothed by using a simple moving average filter, at an interval of every 11 data. In the three test blocks determined, the period with the greatest stability was during the $\mathrm{VO}_{2}$ smoothed curves $\left(\mathrm{VO}_{2 \text { test }}\right)$.

The net metabolic power of the tests was determined by subtracting the $\mathrm{VO}_{2}$ orthostastic from the $\mathrm{VO}_{2 \text { test }}$. The CT was obtained by multiplying the corresponding amount to the net metabolic power by the conversion constant corresponding to the amount of oxygen consumed per gram of substrate, which is equal to 20.1, and expressed data in $\mathrm{J} \cdot \mathrm{kg}^{-1} \cdot \mathrm{min}^{-1}$. The yield of $1 \mathrm{~mL} \mathrm{O} \mathrm{O}_{2}$ consumption in the human body was assumed to oscillate between 19.6 and $21.16 \mathrm{~J}$, corresponding to the variation of the respiratory quotient between 0.71 and 1.00 (Di Prampero, Atchou, Bruckner, \& Moia, 1986). Then, the value obtained was divided by 60 to convert the unit from minutes to seconds $\left(\mathrm{J} \cdot \mathrm{kg}^{-1} \cdot \mathrm{s}^{-1}\right)$ and then divided by the speed performed on the treadmill in meters per second to obtain the CT in $\mathrm{J} \cdot \mathrm{kg}^{-1} \cdot \mathrm{m}^{-1}$.

\section{Statistical Analysis}

For the statistical analysis, we used the SPSS 20 software. Data normality was tested by the Shapiro-Wilk test. Data are presented in descriptive measurements using means with standard deviations or standard error, or median, minimum, and maximum values. A significance level $\alpha=0.05$ was adopted. The description of the sample data characterization were compared by applying unpaired $t$ test.

The verification of low back pain effect (main effect of group) and walking speed effect (main effect of speed) on metabolic power and CT were tested using the generalized estimates of equations (GEE). The statistical model GEE analyzes the data based on the "intent to treat" through the principle of likelihood estimate of missing data.

In the intragroup comparisons, to evaluate the effect of walking speed in each group separately on net metabolic power and CT, Friedman test was used with Wilcoxon signed rank test with correction for number of tests as post hoc test, so that it is accepted as significant when the significance of results was shorter than $\alpha / 3 \quad(<.0167$; Field, 2009).

\section{Results}

The study sample consisted of 18 volunteers (CG: $n=9$; LG: $n=9$ ). Statistical differences in age and anthropometric characteristics were not observed between the groups (Table 1). The median duration of the chronic pain in the LG was 10 years, with the shortest duration being one year and the highest being 30 years. In the LG, the mean pain intensity in the last two months preceding the collection was $6.4 \pm 0.9$. Because there was no difference in anthropometric characteristics, a geometric similarity between the subjects is suggested. In this way, we have chosen not to normalize by the Froude number because this is a measure used to compensate for differences in size (Moretto, Bisiaux, \& Lafortune, 2007).

No significant difference in mean $\mathrm{VO}_{2 \text { orthostatic }}(\mathrm{mL}$ $\mathrm{O}_{2} \cdot \mathrm{kg}^{-1} \cdot \min ^{-1}$ ) was observed between the CG and LG, indicating that the subjects in both groups were equal in this variable at baseline (see Table 2). The speeds did not differ between the groups as well. It can be noted that the $F$ was the same for all the compared speeds, and this was expected since the variations between them was always fixed at $0.5 \mathrm{~km} \cdot \mathrm{hr}^{-1}$.

We did not observed significant group effect as well as a significant group by speed interaction for both variables (net metabolic power: group effect, $p=.790$, and group by speed interaction, $p=.389 ; \mathrm{CT}$ : group effect, $p=.443$, and group by speed interaction, $p=.191$ ). However, there was a main effect of speed for both variables (net metabolic power: $p<.001$; CT: $p<.001)$. The comparisons between different speeds to show the speed effect by GEE can be visualized in Figure 1. 


\begin{tabular}{|c|c|c|c|}
\hline Variable and intergroup comparison & Group & & \\
\hline & & $M$ & $S D$ \\
\hline \multirow{2}{*}{ Age $($ years $) t(11)=-1.266 ; p=.232$} & Control & 37.8 & 7.2 \\
\hline & Low back pain & 43.5 & 8.8 \\
\hline \multirow[t]{2}{*}{$\operatorname{Lll}(\mathrm{m}) t(11)=0.921 ; p=.377$} & Control & 0.91 & 0.06 \\
\hline & Low back pain & 0.88 & 0.05 \\
\hline \multirow{2}{*}{ Stature $(\mathrm{cm}) t(11)=1.521 ; p=.157$} & Control & 176.5 & 8.0 \\
\hline & Low back pain & 170.1 & 6.9 \\
\hline \multirow[t]{2}{*}{ Body mass $(\mathrm{kg}) t(11)=0.199 ; p=.846$} & Control & 76.2 & 10.6 \\
\hline & Low back pain & 77.6 & 14.5 \\
\hline \multirow{2}{*}{$\operatorname{BMI}\left(\mathrm{kg} \cdot \mathrm{m}^{-2}\right) t(11)=-1.096 ; p=.297$} & Control (ideal weight) & 24.4 & 3.0 \\
\hline & Low back pain (overweight) & 26.7 & 4.4 \\
\hline
\end{tabular}

Note . Lll = length of lower limb; BMI $=$ body mass index. Significance level $=.05$.

The intragroup comparisons to evaluate the effect of speed in each group are presented in Figure 2. In CG, the net metabolic power was different between all speeds and we did not observed any difference in the CT. In the LG, the net metabolic power in low speeds was significantly lower than other speeds and the CT was lower in the low speeds than in the PS.

\section{Discussion}

When we assessed the group effect, we found no differences between the CG and LG. Therefore, the first hypothesis of this study, that chronic low back pain compromises walking economy, relative to the control, was not confirmed. It suggests that our results align with those studies showing that chronic back pain does not reduce the physical conditioning, which could be a reason for the LG being less economical than the CG.

While some studies consider that the physical fitness of patients with chronic low back pain is reduced (Duque, Parra, \& Duvallet, 2009), others do not support this finding. The relationship between unconditioning, defined as low cardiovascular capacity and low muscular strength, and chronic low back pain was not observed in a systematic review owing to lack of scientific evidence (Smeets et al., 2006).

Although no difference was found between groups, it should be noted that LG was most economical at low speeds relative to the other speeds.

An outstanding gait feature of people with chronic low back pain is that compared to individuals without low back pain, those with chronic low back pain have significantly slower preferred locomotion speed. It was observed in other studies (Simmonds, Lee, Etnyre, \& Morris, 2012; Simmonds, 2006) but not here. Nevertheless, we can hypothesize that this choice is not free from impairment in the metabolic aspects of walking.

Studies that have assessed walking economy normally express this variable simply as the mean $\mathrm{VO}_{2}$ (Christiansen et al., 2009; Hunter et al., 2005; Sawyer et al., 2010). If this concept had been assumed in this work we could have concluded that the speed would affect the metabolic expenditure of subjects in each group similarly. Noting that the LG, for the net metabolic power, was more economical only in low speeds. The CG, although showed metabolic expenditure growing proportionally to the increase in speed, was also more economical at low speeds. However, for CT, such speed effect differed within each group. While

TABLE 2. Comparison Between Low Back Pain and Control Groups Relating to the Metabolic Power Variables to Evaluate the Effect of the Group

\begin{tabular}{lccc}
\hline \hline Variable & LOW & PS & UP \\
\hline Net metabolic power $\left(\mathrm{mLO}_{2} \cdot \mathrm{kg}^{-1} \cdot \mathrm{min}^{-1}\right)$ & $t(11)=-0.200 ; p=.844$ & $t(11)=-0.079 ; p=.937$ & $t(11)=-0.484 ; p=.637$ \\
Cost of transport $\left(\mathrm{J} \cdot \mathrm{kg}^{-1} \cdot \mathrm{m}^{-1}\right)$ & $t(11)=0.469 ; p=.648$ & $t(11)=-0.762 ; p=.462$ & $t(11)=-0.523 ; p=.611$ \\
\hline
\end{tabular}

Note. Walking intensity below the preferred speed (LOW); preferred speed (PS); intensity walking above the preferred speed (UP). 
ANOVA with repeated measures

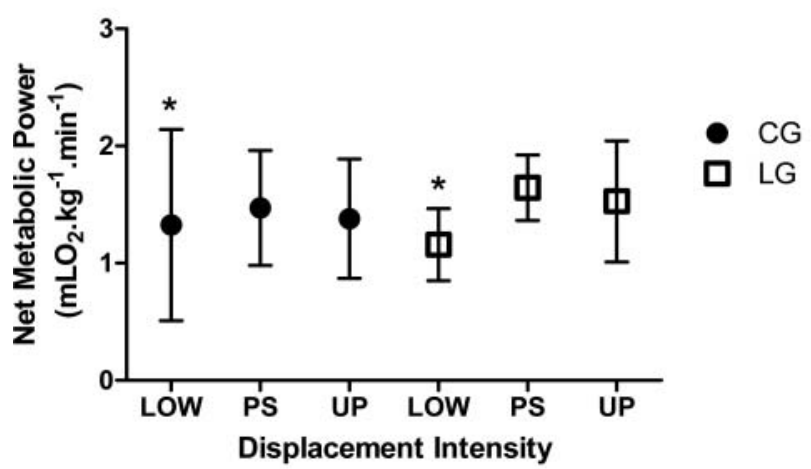

Mauchly $=0.716 ; p=0.433$

$\mathrm{F}(2,12)=8.916 ; \mathrm{p}=0.004$

$\mathrm{Eta}^{2}=0.59$

Net Metabolic Power LG

Mauchly $=0.148 ; \mathrm{p}=0.022$

$\mathrm{F}(1.07,5.39)=8.465 ; \mathrm{p}=0.029$

$\mathrm{Eta}^{2}=0.62$

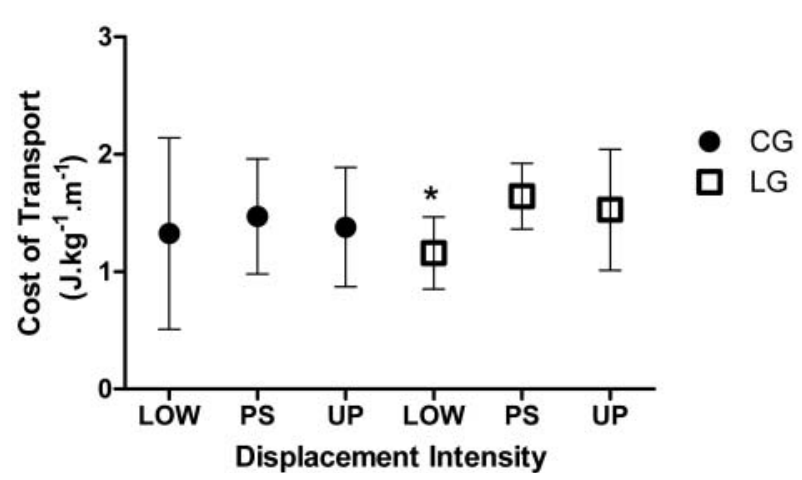

Cost of Transport CG

Mauchly $=0.014 ; \mathrm{p}<0.001$

$\mathrm{F}(1.007,6.042)=0.188 ; \mathrm{p}=0.681$

$\mathrm{Eta}^{2}=0.03$

Cost of Transport LG

Mauchly $=0.378 ; \mathrm{p}=0.143$

$\mathrm{F}(2,10)=4.524 ; \mathrm{p}=0.039$

$\mathrm{Eta}^{2}=0.47$

FIGURE 1. Descriptive statistics and inferential intragroup comparisons for the variables metabolic power and cost of transport by assessing the effect of displacement intensity. Walking intensity below the preferred speed (LOW); preferred speed (PS); walking intensity above the preferred speed (UP); control group (CG); and low back pain group (LG). *Statistical difference LOW compared to PS.

LG was more economical at low speeds, there was no difference in CT at different speeds for the CG.

Although this concern in the way of expressing gait economy has been further discussed in running, we believe that measuring gait economy by simply measuring $\mathrm{VO}_{2}$ may not be adequate, as it does not take into account that the energy equivalent of a certain amount of oxygen may vary depending on the metabolized substrate. Thus, the unit conversion $\mathrm{mL} \mathrm{O}_{2}$ to joules $(\mathrm{J})$ or watts $(\mathrm{W})$ is a more accurate expression of this measure (Di Prampero, Atchou, Bruckner, \& Moia, 1986; Fletcher, Esau, \& Macintosh, 2009).

Although there is now a reasonable and reliable understanding of the basic mechanisms related to biochemical processing that culminate in energy production (Burton, Stokes, \& Hall, 2004; Ferrannini, 1988), this does not occur in relation to the knowledge of the percentage of this energy that the various tissues, especially the muscles, use to produce stability and movement. However, both the amount of active tissues (muscular volume) and the intensity in which the task is accomplished were suggested to affect the use of metabolic energy (Kramer \& Sylvester, 2011).
One of the bases for the primary hypothesis of this study, that the people with chronic low back pain would be less economical than the healthy ones, was the reports about the biomechanical changes in these patients. Patients with chronic low back pain showed little skilled in postural control and to stabilization of the spine during a self-initiated perturbation (Mehta, Cannella, Smith, \& Silfies, 2010). It is speculated that if this deficiency persists for dynamic and cyclical activities, such as walking, there is greater muscle demand and hence higher metabolic energy expenditure.

The CT in low back pain has not been investigated much in the literature. But there is the possibility that changes in spatiotemporal parameters due to low back pain can compromise the walking energy-minimizer mechanisms, especially because this subjects tend to have an en block style of walking due to a loss of coordinative movement between trunk and pelvis, which can compromise the changes in mechanical energies of center of mass by reducing vertical oscillation of the center of mass (Carvalho et al., 2015).

The inverted pendulum model, which is a mechanical model that represent the behavior of the body center of 


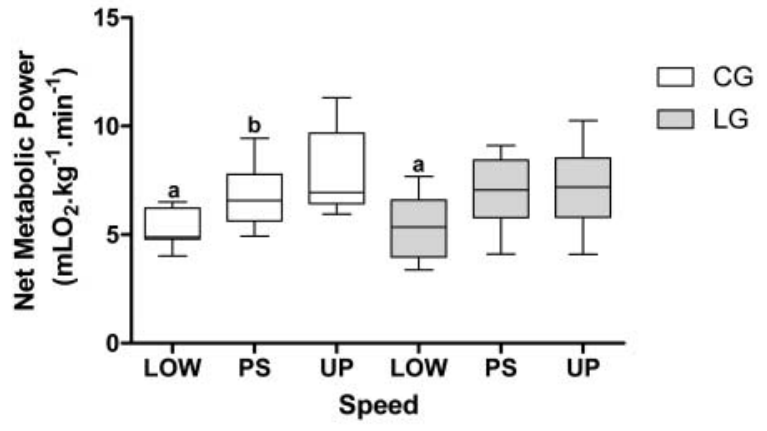

\author{
Net Metabolic Power CG \\ Friedman Test \\ $X^{2}(2)=18.00 ; p<0.001$ *
}

Post-hoc:

Wilcoxon Signed Ranks Test with correction for number of tests.

(1-tailed)

LOW X PS: $\mathbf{T}=\mathbf{0 . 0} ; \mathbf{p}=\mathbf{0 . 0 0 2}$ *

LOW X UP: $\mathbf{T}=\mathbf{0 . 0} ; \mathbf{p}=\mathbf{0 . 0 0 2}$ *

PS X UP: $\mathbf{T}=\mathbf{0 . 0} ; \mathbf{p}=\mathbf{0 . 0 0 2}$ *

\title{
Net Metabolic Power LG \\ Friedman Test \\ $X^{2}(2)=11.556 ; p=0.001 *$
}

Post-hoc:

Wilcoxon Signed Ranks Test with correction for number of tests. (1-tailed)

LOW X PS: $\mathbf{T}=\mathbf{0 . 0} ; \mathbf{p}=\mathbf{0 . 0 0 2}$ *

LOW X UP: $\mathbf{T}=\mathbf{2 . 0} ; \mathbf{p}=\mathbf{0 . 0 0 6}$ *

PS X UP: $\mathbf{T}=\mathbf{3 . 8 3} ; \mathbf{p}=\mathbf{0 . 5 0 0}$

\section{Cost of Transport CG \\ Friedman Test}

$X^{2}(2)=2.667 ; p=0.328$

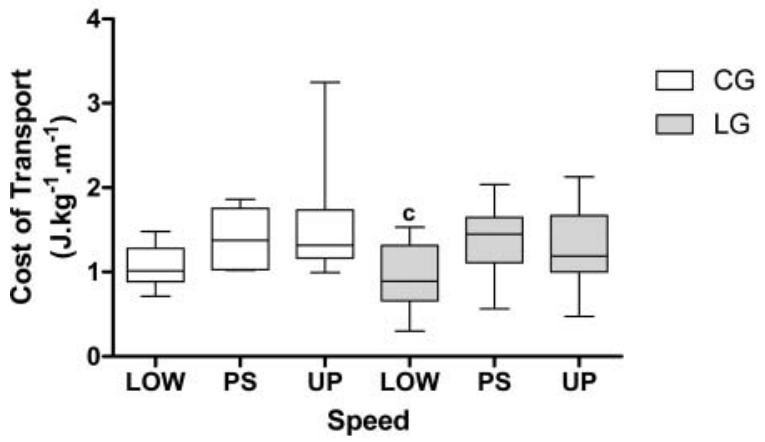

\author{
Cost of Transport LG \\ Friedman Test \\ $X^{2}(2)=11.556 ; p=0.001$ * \\ Post-hoc: \\ Wilcoxon Signed Ranks Test with \\ correction for number of tests.
}

(1-tailed)

LOW X PS: $\mathbf{T}=\mathbf{0 . 0} ; \mathbf{p}=\mathbf{0 . 0 0 2}$
LOW X UP: $\mathbf{T}=\mathbf{3 . 5} ; \mathbf{p}=\mathbf{0 . 0 3 7}$
PS X UP: $\mathbf{T}=\mathbf{4 . 8 3} ; \mathbf{p}=\mathbf{0 . 2 4 8}$

FIGURE 2. Descriptive statistics (median, minimum, and maximum) and intragroup comparisons for the variables metabolic power and cost of transport by assessing the effect of speed in each group separately. Walking speed $0.5 \mathrm{~km} \cdot \mathrm{hr}^{-1}$ slower than the preferred self-selected speed (LOW); preferred self-selected speed (PS); speed $0.5 \mathrm{~km} \cdot \mathrm{hr}^{-1}$ faster than the preferred self-selected speed (UP); control group (CG); low back pain group (LG). *Statistical difference. Statistical difference LOW compared to PS and UP (a); Statistical difference PS compared to UP (b). Statistical difference LOW compared to PS (c). For post hoc: It is accepted as significant when the significance of results was shorter than $\alpha / 3(<.0167)$.

mass, has been used to explain how walking employs and saves mechanical energy. According to this model, the mechanical energies (kinetic and potential) change in terms of phase opposition (while one of them reaches a minimum value, the other reaches a maximum value) during unipodal phase, allowing an interchange between kinetic and potential energies. This energy fluctuation reduces the mechanical work imposed by the muscular system, thanks to the metabolic energy conservation (Gomeñuka, Bona, Rosa, \& Peyré-Tartaruga, 2014; Neptune, Zajac, \& Kautz, 2004; Saibene \& Minetti, 2003).

In optimal speed, that in normal conditions matches preferred self-select speed, the body's ability to reconvert one energy type into another is maximal and the metabolic 
expenditure is minimum and, because of this, the CT is shorter than other speeds. To walk below optimal speed requires greater muscle activity to compensate for the greater instability and, therefore, there is a higher CT (Saibene \& Minetti, 2003). We expected that this would be confirmed in our results.

The electromyographic (EMG) evaluation of the muscle activities of the longissimus, multifidus, and iliocostalis during treadmill walking was conducted in healthy subjects whose pain was induced experimentally by hypertonic saline injection in the spinal muscles. These authors confirmed the motor impairment in the patients with low back pain (with significantly longer support phase than that in the control and shorter balance phase). Moreover, the same authors indicated that in the presence of induced pain, the motor performance of the healthy individuals was also compromised. The patients with back pain also had higher ipsilateral muscle activity in the balance phase on EMG. Volunteers with experimentally induced pain also experienced increased muscle activity on EMG (Moe-Nilssen, Ljunggren, \& Torebjörk, 1999).

The increasing muscular activity could support the primary hypothesis of the present study, which explains why the walking economy in the subjects would be low, as the increasing muscular activity showed an effect on the CT. Probably the discrepancy between the first hypothesis and the present findings are due to nonclear illness etiology, resulting in walking economy similar in control and patients. These mechanisms are still poorly understood.

Similarly, the second hypothesis was refuted. Here, the widely accepted ascendant phase on cost of transport-speed relationship at low speeds (Saibene \& Minetti, 2003) was not found in low back pain. The impairment on pendulum mechanism in these speeds (Carvalho et al., 2015) seems to have been more than compensated by other factor, specifically related to pain.

The two most relevant theories, the vicious cycle and adaptation to pain, that have been used to explain the motor behavior front of the painful stimuli are based on simplistic models that, though consistent with some clinical and experimental observations, are not robust enough to explain the great variability in the findings. The first hypothesis was that the increase in muscle activity in pain is similar, regardless of the task, and that this state of increased activity, once maintained, leads to ischemia with consequent accumulation of pain agents, which generate more pain, leading to a cyclic condition. The second hypothesis was based on decreasing agonist muscle activity but increasing antagonist muscle activity due to painful movement (Hodges \& Tucker, 2011).

A new theory to explain the process of motor adaptation to pain has been proposed. This is based on changes that occur at micro- (in motoneuron discharges) and macrolevels (entire muscle behavior). Adaptation to pain involves the following: (a) redistribution of muscular activation within the muscle itself and between synergistic muscles; (b) changes in mechanical behavior that modify rigidity and movement, which protect against painful stimulation and injury; (c) slight changes in muscle excitability but at multiple levels of the motor system, and these changes can be complementary, supplementary, or competitive; and (d) short-term beneficial effects with harmful consequences in the long term due to tissue overload, decreased movement, and change variability. The stimulus redistribution within the muscle can not only alter the recruited motor units but also activate neuronal pathways that were inactive before the onset of pain, which are often larger motor units that generate higher levels of strength. Therefore, despite the decrease in muscle activity in some pathways that are involved with painful stimulus, other pathways compensate for the decrease. A central premise of this theory is that the activation changes that occur within the muscle and between synergistic muscles produce significant changes in the resultant force production that generates motion. Thus, biomechanical changes accompany the pain condition and the activity redistribution between the trunk muscles that generate kinematic changes and the mechanical properties of the spine (Hodges \& Tucker, 2011). The repercussion of these neurophysiological adjustments on gait energy expenditure of people with low back pain is not known. This is considered as another interesting approach for future studies. Changes in motor standard due to chronic low back pain can have important impact in walking economy.

The present study showed that the subjects in the LG had greater walking economy at low speeds relative to the other speeds, though not statistically different from that of the volunteers in the CG. The main clinical consideration from these findings is whether rehabilitative therapy yields favorable changes in walking speed and in which direction, increasing or decreasing, these changes must occur. This reinforces the need for future research to advance the knowledge on the relationship between chronic low back pain and walking economy. One hypothesis to explain this remarkable finding is that the painful inputs play a role most important than mechanical factors, as the pendulum (Gomeñuka et al., 2014) and dynamical stability (Oliveira, Rosa, Gomeñuka, \& Peyré-Tartaruga, 2013), to determine the optimal walking speed.

Some limitations of the present study should be pointed out. Due to technical limitations, it was not possible to register mechanical parameters related to center of mass. However, to know how the mechanical energies interchange happens, especially at low speeds, allow us to understand whether the largest economy in these speeds is or is not a result of an improvement of energy-minimizing mechanisms. We believe the EMG data acquisition, which could help explain our results, which is one limitation of present study.

The results from our comparisons between the study groups differed from those of previous studies. However, the speeds exerted a significant effect on the net metabolic power in both groups. The effect of the walking speed in 
CT was observed only in the LG. The present study showed that the subjects in the LG had greater walking economy at low speeds relative to the other speeds.

\section{ACKNOWLEDGMENTS}

This study would not have been possible without the assistance of CNPq. The authors are grateful to the Locomotion Group of UFRGS for their insights in the discussions and their comments. They also thank the Unioeste Physical Rehabilitation Center (Centro de Reabilitação Física da Unioeste) and Biological and Health Sciences Center (Centro de Ciências Biológicas e da Saúde [CCBS])/UNIOESTE, - Cascavel, PR, Brazil.

\section{REFERENCES}

Al-Obaidi, S. M., Al-Zoabi, B., Al-Shuwaie, N., Al-Zaabie, N., \& Nelson, R. M. (2003). The influence of pain and pain-related fear and disability beliefs on walking velocity in chronic low back pain. International Journal of Rehabilitation Research, 26, 101-108. doi:10.1097/00004356-200306000-00004

Brumagne, S., Janssens, L., Janssens, E., \& Goddyn, L. (2008). Altered postural control in anticipation of postural instability in persons with recurrent low back pain. Gait \& Posture, 28, 657662.

Brumagne, S., Janssens, L., Knapen, S., Claeys, K., \& SuudenJohanson, E. (2008). Persons with recurrent low back pain exhibit a rigid postural control strategy. European Spine Journal, 17, 1177-1184.

Burton, D. A., Stokes, K. A., \& Hall, G. M. (2004). Physiological effects of exercise. Continuing Education in Anaesthesia Critical Care and Pain, 4, 185-188. doi:10.1093/bjaceaccp/mkh050

Carvalho, A. R., Andrade, A., \& Peyré-Tartaruga, L. A. (2015). Possible changes in energy-minimizer mechanisms of locomotion due to chronic low back pain-a literature review. Revista Brasileira de Reumatologia (English Edition), 55, 55-61. doi:10.1016/j.rbre.2014.01.005

Chou, R., Qaseem, A., Snow, V., Casey, D., Cross, T. J., Shekelle, P., \& Owens, D. K. (2007). Diagnosis and treatment of low back pain: A joint clinical practice guideline from the American College of Physicians and the American Pain Society. Annals of Internal Medicine, 147, 478-491. doi:147/7/478 [pii]

Christiansen, C. L., Schenkman, M. L., McFann, K., Wolfe, P., \& Kohrt, W. M. (2009). Walking economy in people with Parkinson's disease. Movement Disorders, 24, 1481-1487. doi:10.1002/mds.22621.Walking

Cunningham, C. B., Schilling, N., Anders, C., \& Carrier, D. R. (2010). The influence of foot posture on the cost of transport in humans. The Journal of Experimental Biology, 213, 790-797. doi:10.1242/jeb.038984

Di Prampero, P. E., Atchou, G., Bruckner, J. C., \& Moia, C. (1986). The energetics of endurance running. European Journal of Applied Physiology, 55, 259-266.

Dingwell, J. B., \& Marin, L. C. (2006). Kinematic variability and local dynamic stability of upper body motions when walking at different speeds. Journal of Biomechanics, 39, 444-452. doi:10.1016/j.jbiomech.2004.12.014

Donelan, J. M., Kram, R., \& Kuo, A. D. (2001). Mechanical and metabolic determinants of the preferred step width in human walking. Proceedings of the Royal Society B: Biological Sciences, 268(1480), 1985-1992.
Duque, I., Parra, J. H., \& Duvallet, A. (2009). Physical deconditioning in chronic low back pain. Journal of Rehabilitation Medicine, 41, 262-266. doi:10.2340/16501977-0324

Ehrlich, G. E. (2003). Low back pain. Bulletin of the World Health Organization, 81, 671-676.

Elbaz, A., Mirovsky, Y., Mor, A., Enosh, S., Debbi, E., Segal, G., \& Debi, R. (2009). A novel biomechanical device improves gait pattern in patient with chronic nonspecific low back pain. Spine, 34, E507-E512. doi:10.1097/ BRS.0b013e3181a98d3f

Ferrannini, E. (1988). The theoretical bases of indirect calorimetry: A review. Metabolism: Clinical and Experimental, 37, 287-301. doi:10.1016/0026-0495(88)90110-2

Field, A. (2009). Descobrindo a estatística usando o SPSS [Discovering statistics using SPSS] (2nd ed.). Porto Alegre/RS, Brazil: Artmed.

Fletcher, J. R., Esau, S. P., \& Macintosh, B. R. (2009). Economy of running: Beyond the measurement of oxygen uptake. Journal of Applied Physiology, 107, 1918-1922. doi:10.1152/ japplphysiol.00307.2009

Gomeñuka, N. A., Bona, R. L., Rosa, R. G., \& Peyré-Tartaruga, L. A. (2014). Adaptations to changing speed, load, and gradient in human walking: Cost of transport, optimal speed, and pendulum. Scandinavian Journal of Medicine and Science in Sports, 24, E165-E173. doi:10.1111/sms.12129

Heneweer, H., Staes, F., Aufdemkampe, G., van Rijn, M., \& Vanhees, L. (2011). Physical activity and low back pain: A systematic review of recent literature. European Spine Journal, 20, 826-845. doi:10.1007/s00586-010-1680-7

Hergenroeder, A. L., Wert, D. M., Hile, E. S., Studenski, S. A., \& Brach, J. S. (2011). Association of body mass index with selfreport and performance-based measures of balance and mobility. Physical Therapy, 91, 1223-1234. doi:10.2522/ ptj.20100214

Hodges, P. W., \& Tucker, K. (2011). Moving differently in pain: A new theory to explain the adaptation to pain. Pain, 152, S90S98. doi:10.1016/j.pain.2010.10.020

Huijnen, I. P. J., Verbunt, J. A., Peters, M. L., Delespaul, P., Kindermans, H. P. J., Roelofs, J., \& Seelen, H. A. M. (2010). Do depression and pain intensity interfere with physical activity in daily life in patients with chronic low back pain? Pain, 150, 161-166. doi:10.1016/j.pain.2010.04.021

Hunter, G. R., Bamman, M. M., Larson-Meyer, D. E., Joanisse, D. R., McCarthy, J. P., Blaudeau, T. E., \& Newcomer, B. R. (2005). Inverse relationship between exercise economy and oxidative capacity in muscle. European Journal of Applied Physiology, 94, 558-568. doi:10.1007/s00421-005-1370-z

Koes, B. W., van Tulder, M., Lin, C. W. C., Macedo, L. G., McAuley, J., \& Maher, C. (2010). An updated overview of clinical guidelines for the management of non-specific low back pain in primary care. European Spine Journal, 19, 2075-2094. doi:10.1007/s00586-010-1502-y

Kramer, P. A., \& Sylvester, A. D. (2011). The energetic cost of walking: a comparison of predictive methods. PLoS One, 6(6), e21290. doi:10.1371/journal.pone.0021290

Krismer, M., \& van Tulder, M. (2007). Low back pain (non-specific). Best Practice and Research: Clinical Rheumatology, 21, 77-91. doi:10.1016/j.berh.2006.08.004

Lamoth, C. J. C., Beek, P. J., \& Meijer, O. G. (2002). Pelvis-thorax coordination in the transverse plane during gait. Gait \& Posture, 16, 101-114.

Lamoth, C. J. C., Daffertshofer, A., Meijer, O. G., \& Beek, P. J. (2006). How do persons with chronic low back pain speed up and slow down? Trunk-pelvis coordination and lumbar erector spinae activity during gait. Gait \& Posture, 23, 230-239. doi:10.1016/j.gaitpost.2005.02.006 
Lamoth, C. J. C., Meijer, O. G., Wuisman, P. I. J. M., van Dieën, J. H., Levin, M. F., \& Beek, P. J. (2002). Pelvis-thorax coordination in the transverse plane during walking in persons with nonspecific low back pain. Spine, 27, E92-E99. doi:10.1097/ 00007632-200202150-00016

Leerar, P. J., Boissonnault, W., Domholdt, E., \& Roddey, T. (2007). Documentation of red flags by physical therapists for patients with low back pain. The Journal of Manual \& Manipulative Therapy, 15, 42-49. doi:10.1179/106698107791090105

Leurs, F., Ivanenko, Y. P., Bengoetxea, A., Cebolla, A. M., Dan, B., Lacquaniti, F., \& Cheron, G. A. (2011). Optimal walking speed following changes in limb geometry. The Journal of Experimental Biology, 214, 2276-2282. doi:10.1242/jeb.054452

Mahaudens, P., Detrembleur, C., Mousny, M., \& Banse, X. (2009). Gait in adolescent idiopathic scoliosis: Energy cost analysis. European Spine Journal, 18, 1160-1168. doi:10.1007/ s00586-009-1002-0

Mehta, R., Cannella, M., Smith, S. S., \& Silfies, S. P. (2010). Altered trunk motor planning in patients with nonspecific low back pain. Journal of Motor Behavior, 42, 135-144. doi:10.1080/00222891003612789

Moe-Nilssen, R., Ljunggren, A. E., \& Torebjörk, E. (1999). Dynamic adjustments of walking behavior dependent on noxious input in experimental low back pain. Pain, 83, 477-485.

Moretto, P., Bisiaux, M., \& Lafortune, M. A. (2007). Froude number fractions to increase walking pattern dynamic similarities: Application to plantar pressure study in healthy subjects. Gait and Posture, 25, 40-48. doi:10.1016/j.gaitpost.2005.12.010

Negrini, S., Fusco, C., Atanasio, S., Romano, M., \& Zaina, F. (2008). Low back pain: State of art. European Journal of Pain Supplements, 2, 52-56. doi:10.1016/S1754-3207(08)70066-X

Neptune, R. R., Zajac, F. E., \& Kautz, S. A. (2004). Muscle mechanical work requirements during normal walking: The energetic cost of raising the body's center-of-mass is significant. Journal of Biomechanics, 37, 817-825. doi:10.1016/j. jbiomech.2003.11.001

Oliveira, H. B., Rosa, R. G., Gomeñuka, N. A., \& Peyré-Tartaruga, L. A. (2013). Estabilidade dinâmica da caminhada de indivíduos hemiparéticos: a influência da velocidade [Dynamic stability in stroke walking: the influence of speed]. Revista de Educação Física/UEM, 24, 559-565. doi:10.4025/reveducfis.v24.4.21872

Pontzer, H., Raichlen, D. A., \& Sockol, M. D. (2009). The metabolic cost of walking in humans, chimpanzees, and early hominins. Journal of Human Evolution, 56, 43-54. doi:10.1016/j. jhevol.2008.09.001
Saibene, F., \& Minetti, A. E. (2003). Biomechanical and physiological aspects of legged locomotion in humans. European Journal of Applied Physiology, 88, 297-316. doi:10.1007/ s00421-002-0654-9

Sawyer, B. J., Blessinger, J. R., Irving, B. A., Weltman, A., Patrie, J. T., \& Gaesser, G. A. (2010). Walking and running economy: Inverse association with peak oxygen uptake. Medicine and Science in Sports and Exercise, 42, 2122-2127.

Simmonds, M. J. (2006). Measuring and managing pain and performance. Manual Therapy, 11, 175-179. doi:10.1016/j. math.2006.03.002

Simmonds, M. J., Lee, C. E., Etnyre, B. R., \& Morris, G. S. (2012). The influence of pain distribution on walking velocity and horizontal ground reaction forces in patients with low back pain. Pain Research and Treatment, 2012, 214980. doi: $10.1155 / 2012 / 214980$

Skoyles, J. R. (2006). Human balance, the evolution of bipedalism and dysequilibrium syndrome. Medical Hypotheses, 66, 1060 1068.

Smeets, R. J. E. M., Wade, D., Hidding, A., Van Leeuwen, P. J. C. M., Vlaeyen, J. W. S., \& Knottnerus, J. A. (2006). The association of physical deconditioning and chronic low back pain: A hypothesis-oriented systematic review. Disability and Rehabilitation, 28, 673-693. doi:10.1080/09638280500264782

Smeets, R. J., van Geel, K. D., \& Verbunt, J. A. (2009). Is the fear avoidance model associated with the reduced level of aerobic fitness in patients with chronic low back pain? Archives of Physical Medicine and Rehabilitation, 90, 109-117. doi:10.1016/j. apmr.2008.07.009

Waters, R. L., \& Mulroy, S. (1999). The energy expenditure of normal and pathologic gait. Gait and Posture, 9, 207-231. doi:10.1016/S0966-6362(99)00009-0

Welch, E. (2012). Low back pain. InnovAiT, 5, 13-21. doi:10.1093/innovait/inr064

Wert, D. M., Brach, J., Perera, S., \& van Swearingen, J. M. (2010). Gait biomechanics, spatial and temporal characteristics, and the energy cost of walking in older adults with impaired mobility. Physical Therapy, 90, 977-985. doi:10.2522/ptj.20090316

Wittink, H., Hoskins Michel, T., Wagner, A., Sukiennik, A., \& Rogers, W. (2000). Deconditioning in patients with chronic low back pain: fact or fiction? Spine, 25, 2221-2228.

Received March 1, 2015

Revised May 30, 2015

Accepted July 18, 2015 